\title{
Nonlinear Dynamic Behaviors of Rotated Blades with Small Breathing Cracks Based on Vibration Power Flow Analysis
}

\author{
Hailong Xu, ${ }^{1}$ Zhongsheng Chen, $^{1,2}$ Yeping Xiong, ${ }^{2}$ Yongmin Yang, ${ }^{1}$ and Limin Tao ${ }^{1}$ \\ ${ }^{1}$ Science and Technology on Integrated Logistics Support Laboratory, National University of Defense Technology, \\ Changsha 410073, China \\ ${ }^{2}$ Faculty of Engineering and the Environment, University of Southampton, Southampton SO16 7QF, UK
}

Correspondence should be addressed to Zhongsheng Chen; chenzhongsheng@nudt.edu.cn

Received 12 April 2016; Accepted 29 June 2016

Academic Editor: Athanasios Chasalevris

Copyright (C) 2016 Hailong Xu et al. This is an open access article distributed under the Creative Commons Attribution License, which permits unrestricted use, distribution, and reproduction in any medium, provided the original work is properly cited.

\begin{abstract}
Rotated blades are key mechanical components in turbomachinery and high cycle fatigues often induce blade cracks. Accurate detection of small cracks in rotated blades is very significant for safety, reliability, and availability. In nature, a breathing crack model is fit for a small crack in a rotated blade rather than other models. However, traditional vibration displacements-based methods are less sensitive to nonlinear characteristics due to small breathing cracks. In order to solve this problem, vibration power flow analysis (VPFA) is proposed to analyze nonlinear dynamic behaviors of rotated blades with small breathing cracks in this paper. Firstly, local flexibility due to a crack is derived and then time-varying dynamic model of the rotated blade with a small breathing crack is built. Based on it, the corresponding vibration power flow model is presented. Finally, VPFA-based numerical simulations are done to validate nonlinear behaviors of the cracked blade. The results demonstrate that nonlinear behaviors of a crack can be enhanced by power flow analysis and VPFA is more sensitive to a small breathing crack than displacements-based vibration analysis. Bifurcations will occur due to breathing cracks and subharmonic resonance factors can be defined to identify breathing cracks. Thus the proposed method can provide a promising way for detecting and predicting small breathing cracks in rotated blades.
\end{abstract}

\section{Introduction}

High-speed rotated blades are widely used in modern industry, such as compressor blades, turbine blades, and fan blades. During working of rotated blades, they often have to be exposed to severe environments including strong vibrations, large centrifugal forces, and high temperatures. Thus rotated blades usually cause different kinds of faults under these extreme operation environments. In addition, all blades are ideally assumed to be identical, leading to a tuning bladed disc. In practice, however, each blade on a disc is always slightly different from others due to manufacturing tolerances, variations in material properties, and so forth. These small differences called mistuning can lead to a huge variation of forced vibration response across a set of blades. For example, a $5 \%$ variation in the blade cantilever frequencies on a 92-bladed turbine disc could lead to one blade suffering response levels which were over $500 \%$ of those observed on a tuning bladed disc $[1,2]$. Thus, mistuning will also accelerate some blades to fail due to high cycle fatigues. Statistic data have shown that over $60 \%$ of the overall faults are caused by vibrations. Furthermore, blade faults have accounted for more than $70 \%$ of vibration-induced faults. In particular, blade cracks caused by high cycle fatigues are one class of dangerous faults. If a small fatigue crack occurs in a blade, it will expand quickly under complex loads. Then catastrophic consequences may happen, which will cause a great deal of loss. Thus, from the viewpoint of safety, reliability, and availability, it is a prompt requirement to accurately detect small cracks in rotated blades as early as possible [3].

Up to now, many methods have been studied to detect and identify cracks. According to [4,5], cracks in a structure may cause changes in mass distribution and damping properties. This approach suffers from various limitations mainly from the fact that the modification of the stress field induced by the crack is decaying with the distance from the crack. Moreover, these parameters are difficult to be measured accurately. The fact that a crack inevitably affects dynamic 
responses of a structural member was known long ago [6]. Vibration monitoring has revealed a great potential for damage identification. Numerous attempts to quantify local defects are reported in the literature. According to existing literatures, dynamic models of rotated blades with cracks can be divided into two categories: linear and nonlinear models. As for linear models, in general, there exist three basic crack models configurations: the local flexibility model [7-9], the local bending moment [10], and the equivalent reduced cross section model [11]. For example, a cracked blade was modeled by using two uniform segments connected by a massless torsional spring at the location of the crack $[12,13]$ or using two segments connected by extensional and rotational massless springs at the location of the crack [14, 15]. Local flexibility was used to represent a crack in a blade, where the local flexibility was calculated based on the stress intensity factor. Then equivalent stiffness of a cracked blade could be calculated by the local flexibility [7-9]. The advantages of linear models include the fact that theoretical foundations are mature and they are easy to be solved analytically. Thus, dynamic behaviors and parameters of a cracked blade can be easily calculated and observed. In practice, however, dynamic behaviors of a cracked blade are in essence rather nonlinear than linear. While nonlinear features cannot be extracted from linear vibration model of a cracked blade, it is not easy to accurately detect the crack.

In order to overcome the drawbacks of linear models, nonlinear dynamic models have been widely used to model a cracked blade. As for cracks in blades, they were always assumed to be either open or close all the time in early studies. In practice, however, a crack will open and close alternatively during vibrating, which is called a breathing crack. In particular, an initial crack in blades is rather like a breathing one than an open or close one. In order to represent time-varying characteristics of a breathing crack, different nonlinear models have been proposed. By assuming that bilinearity was introduced by a breathing crack, square wave functions were presented to model it [16-19]. In [20], a quadratic stiffness term was used to model a breathing crack by considering its weak nonlinearity. By considering continuous opening and closing process of a breathing crack, cosine function-based models have been proposed [21-23]. In [24], a crack was equivalent to the change of local stiffness and then a nonlinear amplitude-dependent function was used to model a breathing crack. In addition, contact-based two-dimensional finite element models have already been studied to model breathing cracks [19, 25-27]. So it can be summarized that traditional nonlinear dynamic analysis of a blade with a breathing crack is mainly based on vibration displacements, which has been testified to be much effective for large cracks. But when cracks are small, they may cause weak nonlinearity and have little effect on vibration displacements. Under this case, it will be very difficult to extract nonlinear features of small cracks from vibration displacements.

The fundamental concept of power flow was first proposed by Goyder and White [28]. Vibration power flow analysis (VPFA) provides a novel way to describe dynamic behaviors of complex structures and coupled systems, which focuses on the flow of vibration energy rather than the detailed spatial pattern of the structural response. Many researchers have used different VPFA methods to analyze linear dynamic systems $[29,30]$. More recently, VPFA methods have been extended to nonlinear systems. Yang et al. [31] studied the nonlinear power flow characteristics of a twodegrees-of-freedom system with nonlinear stiffness created by a pair of oblique springs. Compared with displacementsbased vibration analysis, VPFA combines the effects of force, velocity amplitudes, and relative phase angles, so it can better depict vibration energy transmission in mechanical structures or systems. By this way, it can enlarge nonlinear effects of a small breathing crack on blade vibrations. Thus, VPFA may be more sensitive to extract nonlinear features than displacements-based vibration analysis. So VPFA provides an effective way to solve the above problem. However, related works have not been addressed by now.

In this paper, the VPFA method is introduced for nonlinear dynamics analysis of rotated blades with small breathing cracks. Then nonlinear characteristics due to cracks are analyzed and extracted. The goal of this paper is to expose nonlinear behaviors of rotated blades with small breathing cracks based on the VPFA-based method and validate its superior sensitivity. The left contents are organized as follows. Nonlinear dynamic mode of a blade with a breathing crack is built in Section 2. In Section 3, the corresponding vibration power flow model is presented. Next, numerical simulations are done to validate nonlinear behaviors of the cracked blade based on VPFA in Section 4. Finally, conclusions are marked in Section 5.

\section{Dynamic Modeling of Rotated Blades with a Breathing Crack}

In this paper, a rotated bladed disk with a small breathing crack in a blade is considered and shown as Figure 1. The distance between the breathing crack and the blade tip is denoted as $l_{c}$. The length, width, and height of the blade are denoted as $L, w$, and $h$, respectively. For the sake of simplicity, the disk is assumed to be rigid. Then the rotated cracked blade can be simplified to a cantilever beam as shown in Figure 2. When lateral vibration appears in a cracked blade, the crack keeps opening and closing alternatively during vibrating, which is called a breathing crack in [32]. So a breathing crack is used and analyzed in this paper. In addition, lateral vibration of beams is associated with the time-varying slope of the beam, which will resist rotary acceleration with a rotary inertia force. The effects of the rotary inertia and the shear deformation are better described by the RayleighTimoshenko beam, which can be further reduced to the Euler-Bernoulli beam by keeping the first two terms [33].

Due to manufacturing and assembling errors and so forth, imbalances always occur in a bladed disk, which will cause mechanical excitation. Here, an eccentric force is assumed to act on the rotated blade with a breathing crack. Furthermore, it can be regarded as a harmonic excitation subjected to the free end of the simplified cantilever beam $[34,35]$. 


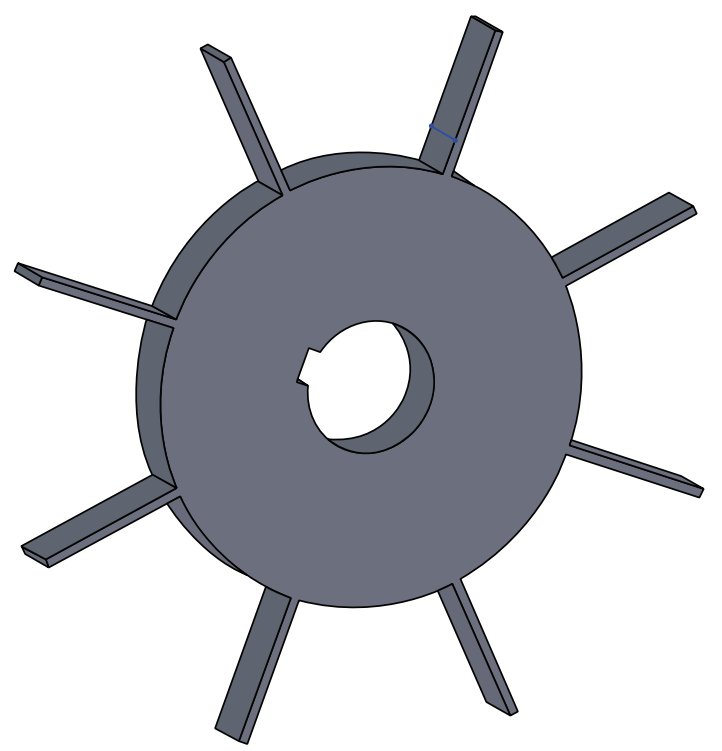

FIGURE 1: 3D model of a rotated bladed disk with a breathing crack.

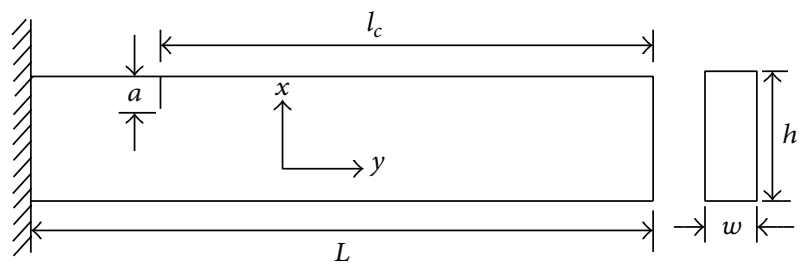

FIGURE 2: Schematic diagram of the equivalent cantilever beam with a breathing crack.

2.1. Derivation of Local Flexibility due to a Crack. As shown in Figure 2, when the equivalent cantilever beam with a small breathing crack is subjected to an external load, additional stress will concentrate near the crack tip. Then local flexibility of the blade at the location of the crack will be changed, so the stiffness of the cracked blade will decrease. Further, the local flexibility due to a crack can be calculated by the stress intensity factor based on Castigliano's theorem at the range of linear elasticity.

Firstly, additional stress energy of the blade due to the crack can be calculated as follows [4]:

$$
U_{T}=\int_{0}^{a} \frac{\partial U_{T}}{\partial a} d a=w \int_{0}^{a} J_{s} d h,
$$

where $a$ is the depth of the crack. $w$ is the width of the cracked blade. $h$ is the thickness of the cracked blade. $J_{s}$ is the density of stress energy which can be calculated as follows:

$$
J_{s}=\frac{1-v^{2}}{E} K^{2}
$$

where $v$ is Poisson's ratio, $E$ is Young's modulus, and $K$ is the stress intensity factor which is given as follows [4]:

$$
K=\sigma_{b} F_{I}(\alpha) \sqrt{\pi a},
$$

where $\sigma_{b}$ is the bending stress and equates to $6 M_{b} / w h^{2} . F_{I}(\alpha)$ is a dimensionless function related to the ratio $(\alpha=a / h)$ of the crack depth to the beam thickness, which can be obtained as follows [4]:

$$
\begin{aligned}
F_{I}(\alpha)= & 1.12-1.4(\alpha)+7.33(\alpha)^{2}-13.1(\alpha)^{3} \\
& +14(\alpha)^{4} .
\end{aligned}
$$

By substituting (2) into (1), one can get the following formula:

$$
U_{T}=\frac{36 \pi\left(1-v^{2}\right)}{E} \frac{M_{b}}{w h^{2}} g(\alpha),
$$

where $g(\alpha)=a^{2}\left(19.60 \alpha^{8}-40.69 \alpha^{7}+47.04 \alpha^{6}-32.99 \alpha^{5}+\right.$ $\left.20.30 \alpha^{4}-9.98 \alpha^{3}+4.60 \alpha^{2}-1.05 \alpha+0.63\right)$.

Then the local flexibility due to the crack in a blade can be calculated as follows [5]:

$$
\Delta c=\frac{72 l_{c}{ }^{2} \pi\left(1-\nu^{2}\right)}{E w h^{4}} g(\alpha) .
$$

Obviously, $\Delta c$ is closely related to both the location and size of a crack, so that it can be used to characterize a crack. In next section, $\Delta c$ will be used to calculate equivalent stiffness of a cracked blade.

2.2. Time-Varying Dynamic Model of the Rotated Blade with a Small Breathing Crack. An eccentric force acts on rotated blades in this paper and the excitation frequency is much smaller than their first-order mode frequencies. So the contributions of higher modes can be negligible. The breathing crack opens and closes alternatively during vibrating, so equivalent stiffness of the cracked blade is time-varying. Then nonlinear behaviors due to the crack will occur in vibration signals of the cracked blade. Under this case, time-varying vibration model of the blade with a breathing crack can be represented by a single-degree-of-freedom (SDOF) lumpedparameter model, as shown in the following equation:

$$
m_{\mathrm{eq}} \ddot{x}+c_{\mathrm{eq}} \dot{x}+k_{\mathrm{eq}}(t) x=m_{\mathrm{eq}} e \omega^{2} \sin \omega t,
$$

where $m_{\text {eq }}, c_{\text {eq }}$, and $k_{\text {eq }}(t)$ are equivalent mass, damper, and stiffness, respectively. $x$ is the vibration displacement. $\omega$ is the rotated angular frequency. $e$ is the eccentricity. Here, a small breathing crack is considered, so the equivalent mass is as $m_{\mathrm{eq}}=0.228 \mathrm{~m}^{\prime} \mathrm{L}$, where $m^{\prime}$ is the unit length mass of the blade [23].

Next, the key problem is how to obtain $k_{\text {eq }}(t)$. For a breathing crack, equivalent stiffness of the cracked blade is always time-varying, so here a cosine function is adopted to represent time-varying stiffness of the blade with a breathing crack; that is,

$$
k_{\mathrm{eq}}(t)=k_{\mathrm{eq}}^{\mathrm{open}}+\frac{1}{2}\left(k_{\mathrm{eq}}^{\mathrm{close}}-k_{\mathrm{eq}}^{\mathrm{open}}\right)(1+\cos (\omega t)) \text {, }
$$

where $k_{\mathrm{eq}}^{\text {open }}$ and $k_{\mathrm{eq}}^{\text {close }}$ are equivalent stiffness of the blade with open and close crack, respectively. 
Centrifugal rigidity will appear in a rotated blade due to centrifugal force. According to [36], the dynamic natural frequency of a rotated blade with a speed of $n$ can be calculated as

$$
f_{d}^{2}=f_{s}^{2}+B n^{2}
$$

where $f_{d}$ and $f_{s}$ are natural frequencies of a rotated and static blade, respectively. $B$ is the calibration factor, which is defined as follows:

$$
B=\left(\frac{\pi}{30}\right)^{2} \frac{\int_{0}^{L}(R+y)\left[\int_{0}^{y}(d z / d y)^{2} d y\right] d y}{\int_{0}^{L} z^{2} d y},
$$

where $R$ is the radius of the disc. $z=\left(\sin \lambda_{r} y-\operatorname{sh} \lambda_{r} y\right)+$ $\zeta_{r}\left(\cos \lambda_{r} y-\operatorname{ch} \lambda_{r} y\right)$ with $\zeta_{r}=\left(\cos \beta_{r}+\operatorname{ch} \beta_{r}\right) /\left(\sin \beta_{r}-\operatorname{sh} \beta_{r}\right)$ and $\lambda_{r}=\beta_{r} / L . r$ is the order. $z$ depends on vibration mode of the blade. Here, the first-order mode is addressed, so we will have $\beta_{r}=\beta_{1}=1.875$.

For the SDOF lumped-parameter model, (9) can be rewritten as follows:

$$
\left(\frac{1}{2 \pi} \sqrt{\frac{k_{\mathrm{eq}}^{\text {close }}}{m_{\mathrm{eq}}}}\right)^{2}=\left(\frac{1}{2 \pi} \sqrt{\frac{k_{\mathrm{eq}}^{\text {static }}}{m_{\mathrm{eq}}}}\right)^{2}+B n^{2},
$$

where $k_{\text {eqs }}^{\text {static }}$ is the equivalent stiffness of the static blade, which can be calculated as $k_{\text {eq }}^{\text {static }}=E I \pi^{4} / 32 L^{3}$. Then, based on (11), the equivalent stiffness of the rotated blade can be calculated as follows:

$$
k_{\mathrm{eq}}^{\text {close }}=k_{\mathrm{eq}}^{\text {static }}+4 \pi^{2} m_{\mathrm{eq}} B n^{2} .
$$

While the crack keeps open fully during vibrating, the total flexibility of the blade with an open crack can be obtained as follows:

$$
c_{\text {open }}=\frac{1}{k_{\text {eq }}^{\text {close }}}+\Delta c .
$$

Then, equivalent stiffness of the blade with an open crack can be calculated as

$$
k_{\mathrm{eq}}^{\mathrm{open}}=\frac{1}{c_{\text {open }}} .
$$

Finally, by combining (7) (14), the time-varying SDOF dynamic model of the rotated blade with a breathing crack can be built as follows:

$$
\begin{aligned}
m_{\mathrm{eq}} \ddot{x} & +c_{\mathrm{eq}} \dot{x} \\
& +\left(k_{\mathrm{eq}}^{\mathrm{open}}+\frac{1}{2}\left(k_{\mathrm{eq}}^{\text {close }}-k_{\mathrm{eq}}^{\mathrm{open}}\right)(1+\cos (\omega t))\right) x \\
= & m_{\mathrm{eq}} e \omega^{2} \sin \omega t .
\end{aligned}
$$

Under this case, natural frequency of the blade with a breathing crack can be calculated as follows [21, 32]:

$$
\omega_{b}=\frac{2 \omega_{\text {close }} \omega_{\text {open }}}{\omega_{\text {close }}+\omega_{\text {open }}},
$$

where $\omega_{\text {close }}=\sqrt{k_{\text {eq }}^{\text {close }} / m_{\mathrm{eq}}}$ and $\omega_{\text {open }}=\sqrt{k_{\mathrm{eq}}^{\text {open }} / m_{\mathrm{eq}}}$. Then $c_{\mathrm{eq}}$ in (15) can be calculated as $c_{\mathrm{eq}}=2 \xi m_{\mathrm{eq}} \omega_{b}$.

In previous studies, vibration displacements $x$ solved from (15) are always utilized to analyze nonlinear characteristics of the breathing crack and extract the corresponding features. However, when the breathing crack is small, vibration displacements-based analysis methods seem to be less sensitive to it.

\section{Vibration Power Flow Model of the Rotated Blade with a Breathing Crack}

In order to accurately identify nonlinear behaviors due to a small breathing crack, the power flow analysis method is adopted here. Firstly, multiplying by velocity $\dot{x}$ on both sides of (7), one can derive the power flow balance equation of the cracked blade in the following form:

$$
m_{\mathrm{eq}} \ddot{x} \dot{x}+c_{\mathrm{eq}} \dot{x} \dot{x}+k_{\mathrm{eq}}(t) x \dot{x}=m_{\mathrm{eq}} e \omega^{2} \dot{x} \sin \omega t .
$$

Further, the power flow model of the blade with a breathing crack can be written as follows:

$$
\dot{K}+\dot{U}+P_{d}=P_{\text {in }}
$$

where $\dot{K}=m_{\mathrm{eq}} \ddot{x} \dot{x}, \dot{U}=k_{\mathrm{eq}}(t) x \dot{x}, P_{d}=c_{\mathrm{eq}} \dot{x} \dot{x}$, and $P_{\text {in }}=$ $m_{\mathrm{eq}} e \omega^{2} \dot{x} \sin \omega t$ are time change rates of kinetic and potential energies and dissipated and input powers, respectively.

In contrast to (7), it can be easily seen that different powers are used as basic physical quantities to analyze the nonlinear system, instead of vibration displacements. Furthermore, one can find that each power is in nature a quadratic term of the displacement and/or velocity, so that the change rate of the displacement may be magnified by using powers. By this way, it seems that VPFA-based methods can be more sensitive to identify a small breathing crack than traditional methods.

\section{Numerical Simulations on Nonlinear Behaviors of the Cracked Blade Based on VPFA}

In order to testify nonlinear behaviors of a blade with a small breathing crack based on the VPFA method, numerical simulations are done here. Material and geometric properties of the rotated blade in simulations are listed in Table 1. According to (7) and (8), the nonlinearity of this system comes from the equivalent stiffness, so next $k_{\text {eq }}(t)$ will be investigated.

4.1. Equivalent Stiffness of the Rotated Blade with a Breathing Crack. Firstly, the depth of the breathing crack is set as $1 \mathrm{~mm}$ and the distance between the crack and the blade tip is set as $40 \mathrm{~mm}$. Other parameters are shown as Table 1 . Based on (8) (14), three equivalent stiffness cases of the blade with different crack models are calculated as shown in Figure 3, where $k_{\text {eq }}^{\text {close }}=99390 \mathrm{~N} / \mathrm{m}, k_{\mathrm{eq}}^{\text {open }}=95120 \mathrm{~N} / \mathrm{m}$, and $k_{\mathrm{eq}}(t)$ 


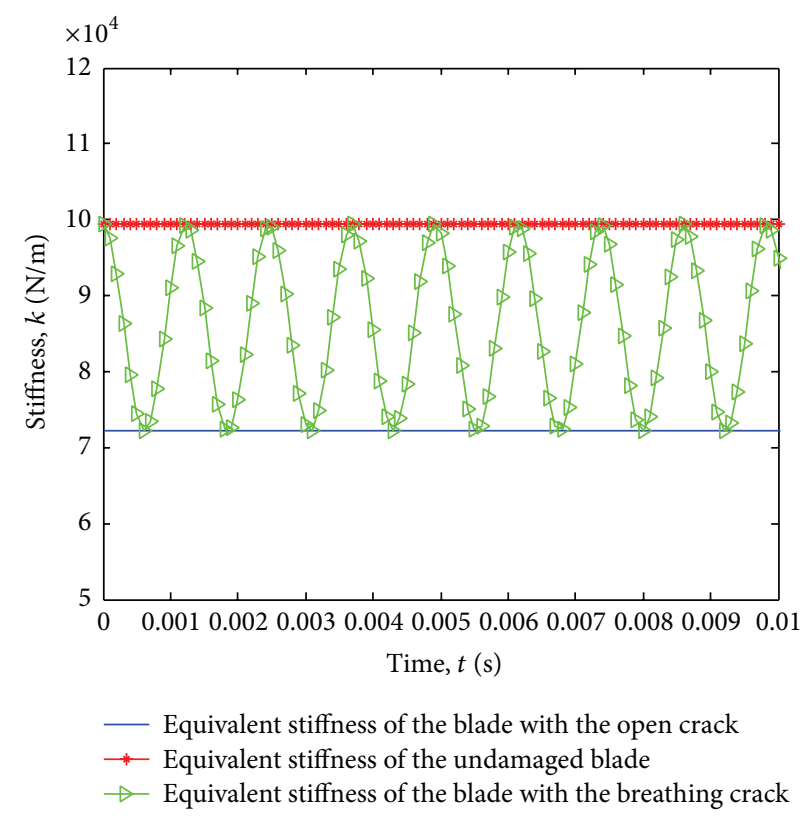

FIGURE 3: Equivalent stiffness of three different crack models.

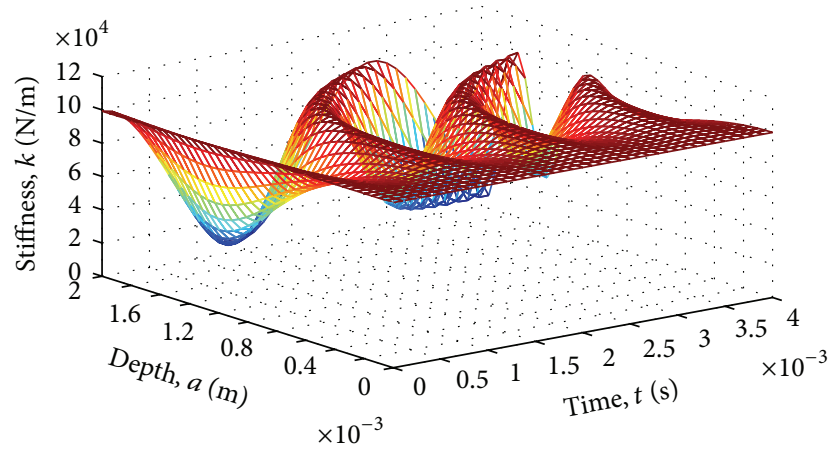

(a)

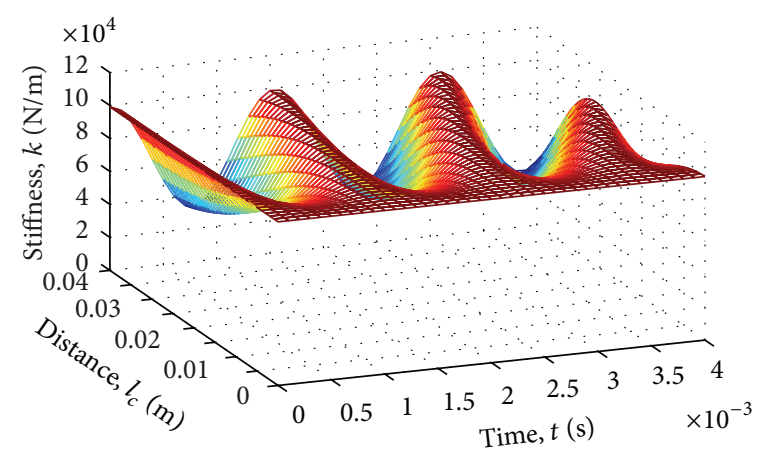

(b)

FIGURE 4: 3D plot of equivalent stiffness of the cracked blade with (a) the depth and (b) the distance.

TABLE 1: Material and geometric properties of the rotated blade.

\begin{tabular}{lcc}
\hline Symbols & Properties & Value \\
\hline$L$ & Length of the blade $(\mathrm{mm})$ & 45 \\
$h$ & Thickness of the blade $(\mathrm{mm})$ & 2 \\
$w$ & Width of the blade $(\mathrm{mm})$ & 20 \\
$R$ & Radius of the disc $(\mathrm{mm})$ & 50 \\
$n$ & Rotated speed $(\mathrm{RPM})$ & 10000 \\
$E$ & Young's modulus $(\mathrm{Pa})$ & $2 \times 10^{11}$ \\
$\nu$ & Poisson's ratio & 0.3 \\
$\rho$ & Density of blade $\left(\mathrm{kg} / \mathrm{m}^{3}\right)$ & 7800 \\
$e$ & Eccentricity $(\mathrm{mm})$ & 10 \\
$\xi$ & Damping ratio & 0.01 \\
\hline
\end{tabular}

is a cosine function. Obviously, the values of $k_{\mathrm{eq}}(t)$ remain between $k_{\mathrm{eq}}^{\mathrm{open}}$ and $k_{\mathrm{eq}}^{\text {close }}$.
It has been pointed out that the depth and position of a breathing crack will influence equivalent stiffness of the cracked blade. Here, the relationships between the equivalent stiffness and the depth and the position are shown in Figure 4. It can be seen that (i) with the increase of the depth equivalent stiffness of the rotated cracked blade will decrease and amplitude of the cosine function will increase. So nonlinearity of the system is strengthened and that (ii) with the increase of the distance between the crack and the blade tip similar results as (i) can be obtained.

\subsection{Nonlinear Power Flow Characteristics of the Blade with a} Breathing Crack. Here the classical Runge-Kutta method is used to solve the above nonlinear equation and calculate $P_{d}$ and $P_{\text {in }}$. Parameters of the small breathing crack are chosen as $a=0.4 \mathrm{~mm}$ and $l_{c}=40 \mathrm{~mm}$. The rotated speed is 10000 RPM and then the excitation frequency is calculated as $\omega_{0}=166.7 \mathrm{~Hz}$. The time-domain and frequency-domain waveforms of $x, P_{d}$, and $P_{\text {in }}$ are calculated and shown in 


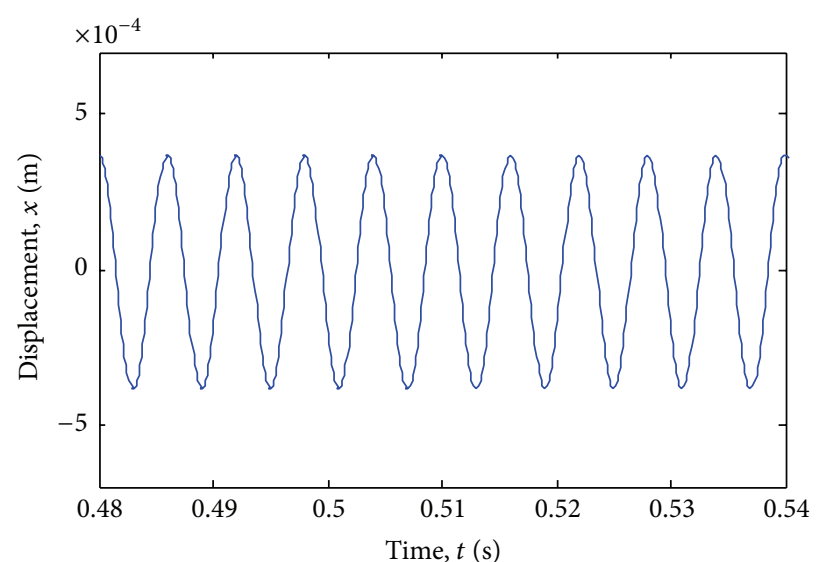

(a)

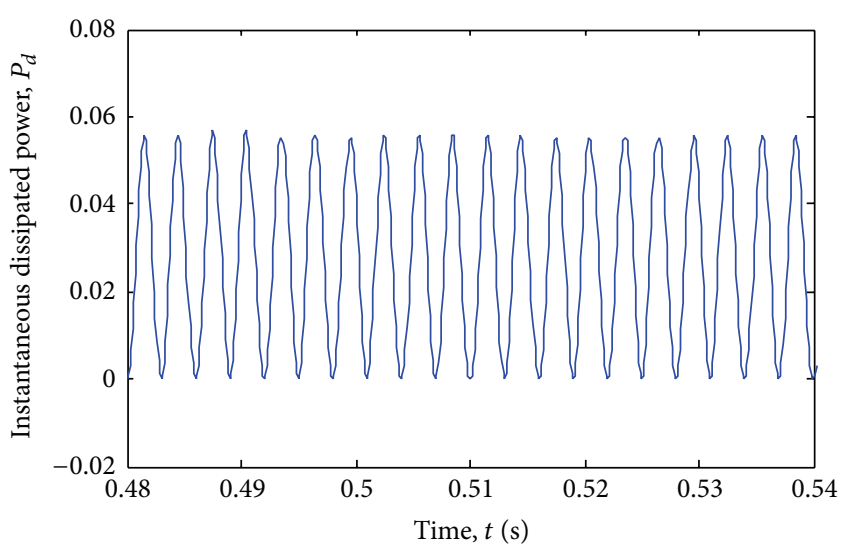

(c)

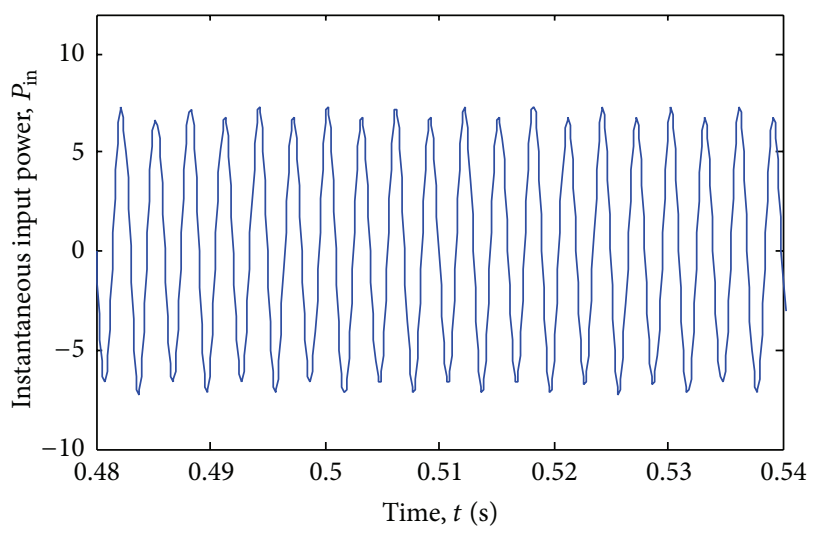

(e)

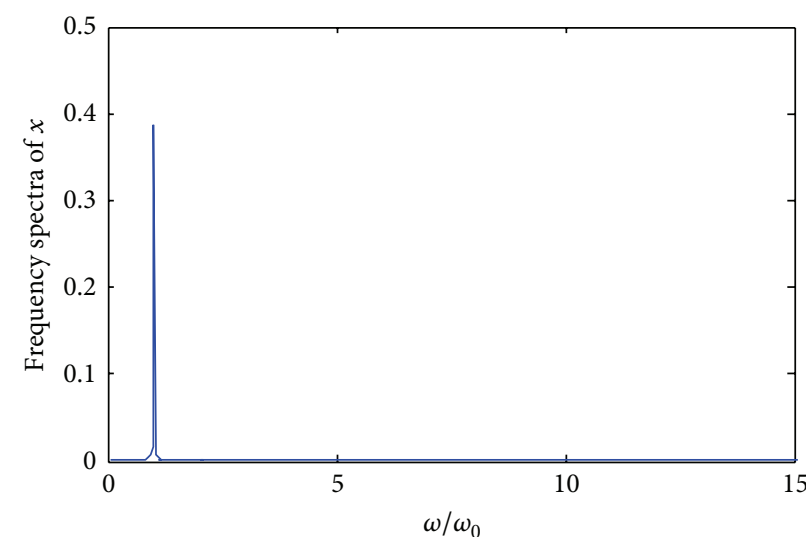

(b)

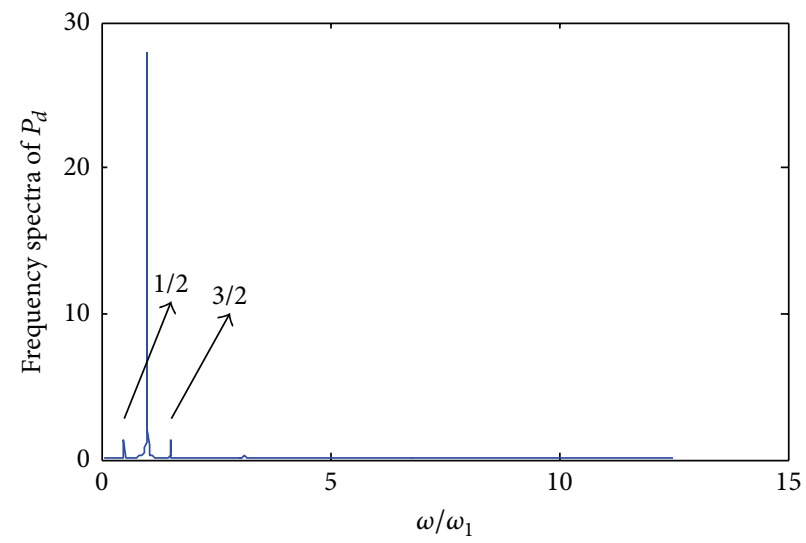

(d)

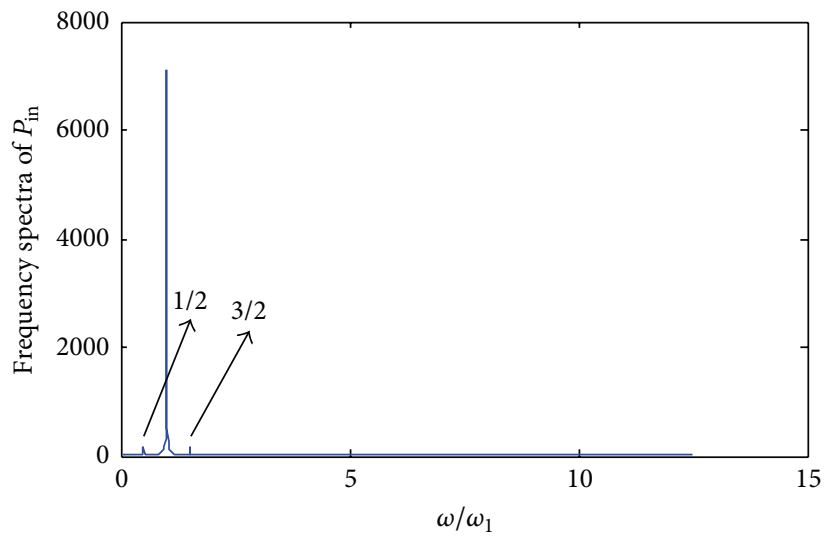

(f)

Figure 5: Time-domain ((a), (c), and (e)) and frequency-domain ((b), (d), and (f)) waveforms of $x, P_{d}$, and $P_{\text {in }}$ when $a=0.4$ mm.

Figures 5(a)-5(f), respectively. Because $P_{d}$ is a quadratic term of velocity and $P_{\text {in }}$ is the product of the excitation and the displacement, the fundamental response frequency should be $\omega_{1}=2 \omega_{0}$.

Comparing Figure 5(b) with Figures 5(d) and 5(f), it can be easily seen that only the harmonic frequency $\omega_{0}$ appears in the frequency response of displacement when the breathing crack is small, while a subharmonic frequency $\left(\omega_{1} / 2\right)$ and a superharmonic frequency $\left(3 \omega_{1} / 2\right)$ except for $\omega_{1}$ also appear in the frequency response of $P_{d}$ and $P_{\text {in }}$.
The reason is that the breathing crack is too small. Thus, one can see that displacement-based analysis is difficult to detect nonlinear behaviors of the cracked blade, while the VPFA-based method is sensitive to achieve it. Furthermore, the depth of the small breathing crack is enlarged to $a=$ $1.2 \mathrm{~mm}$. Numerical simulation results are shown in Figure 6. It can be seen that (i) all amplitudes of frequency responses increase under a larger breathing crack and that (ii) multiple frequencies $\left(2 \omega_{0} \sim 3 \omega_{0}\right)$ except for $\omega_{0}$ appear in the frequency response of displacement when the breathing 


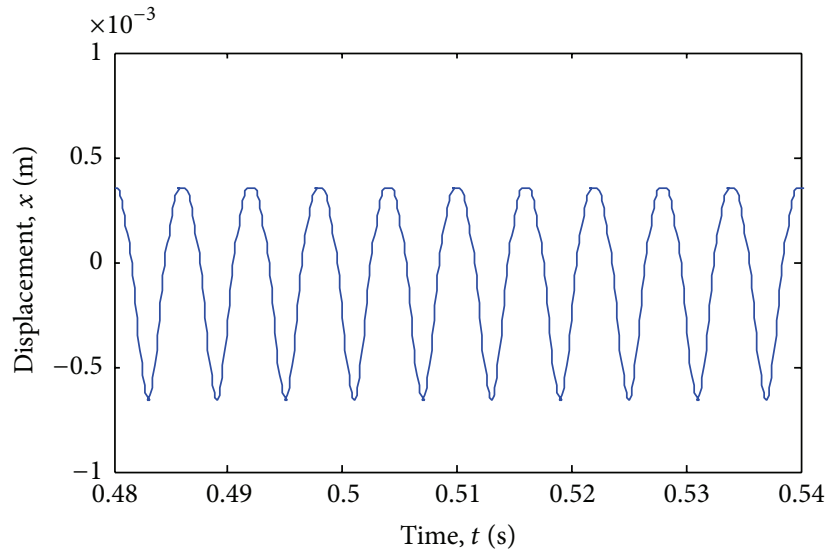

(a)

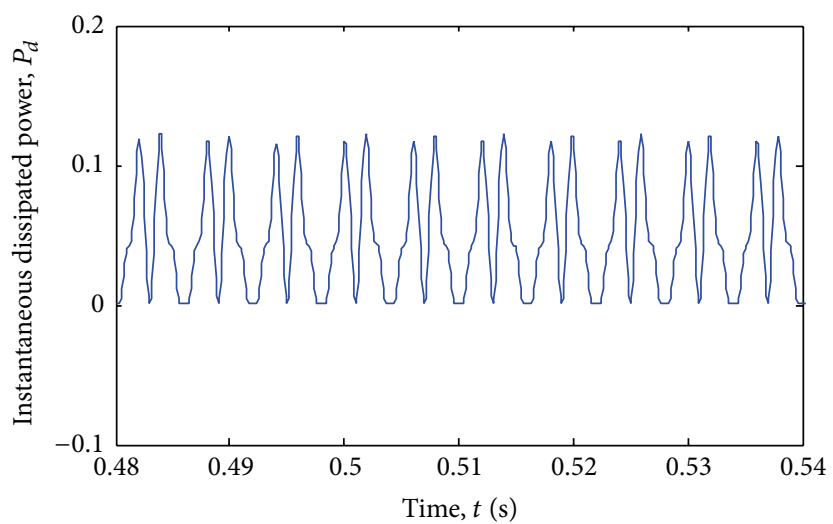

(c)

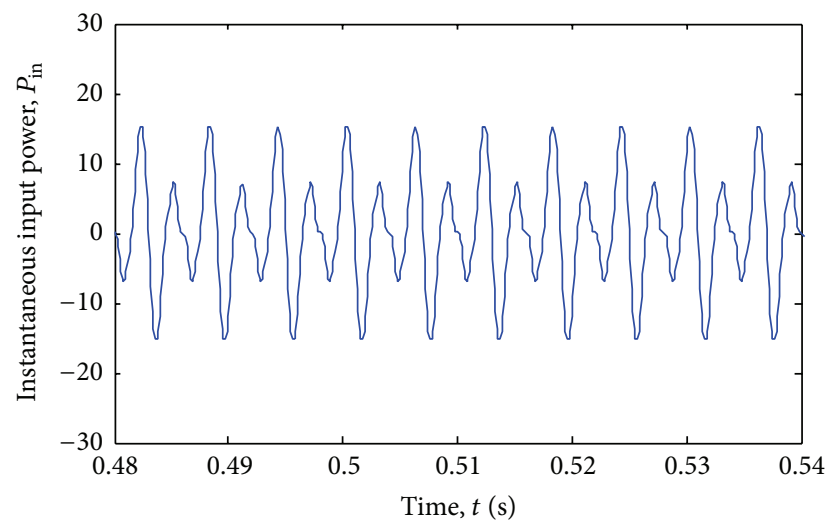

(e)

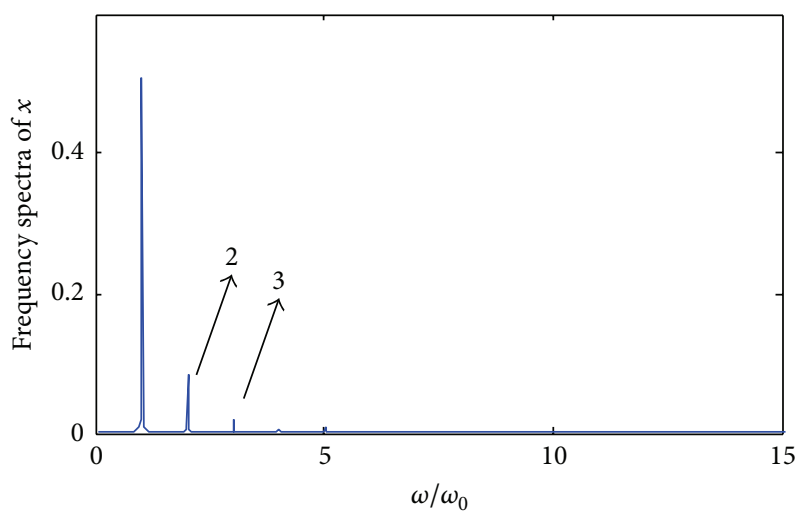

(b)

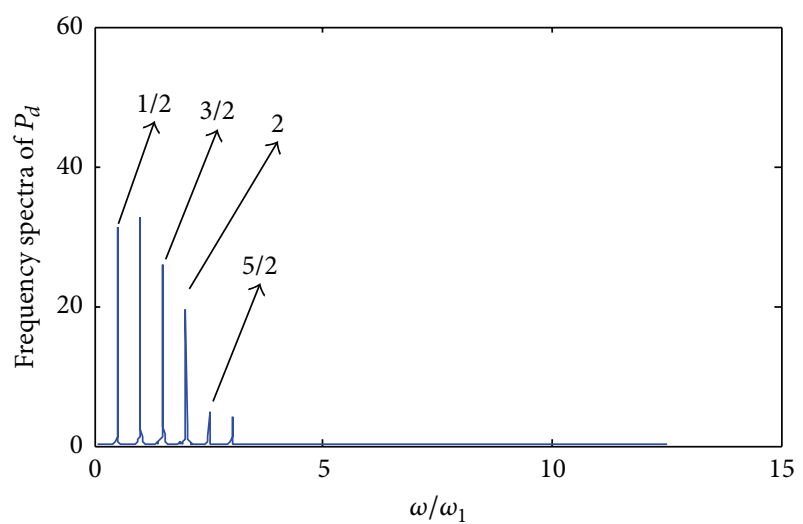

(d)

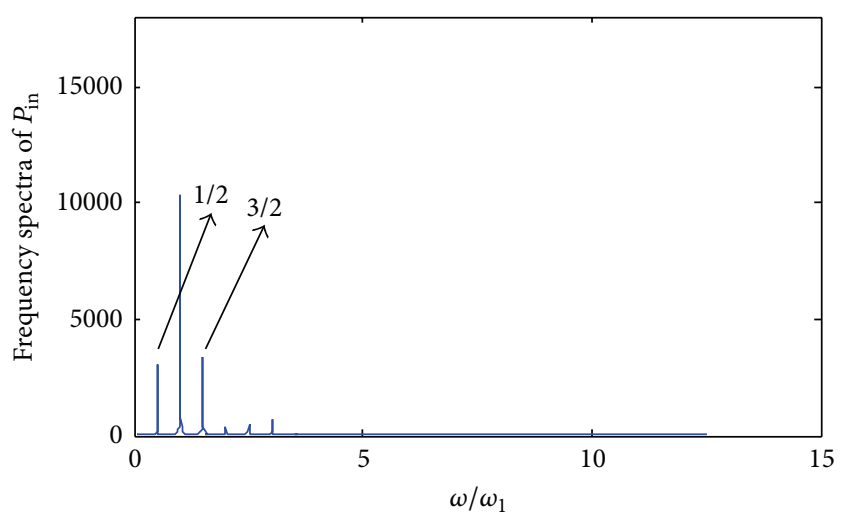

(f)

Figure 6: Time-domain ((a), (c), and (e)) and frequency-domain ((b), (d), and (f)) waveforms of $x$, $P_{d}$, and $P_{\text {in }}$ when $a=1.2$ mm.

crack is enlarged, while more superharmonic frequencies $\left(3 \omega_{1} / 2,2 \omega_{1}, 5 \omega_{1} / 2\right.$, etc. $)$ appear in the frequency responses of $P_{d}$ and $P_{\text {in }}$.

The results in Figures 5 and 6 testify that nonlinear behaviors of a small breathing crack can be enhanced by VPFA, so that small breathing cracks can be easily identified. And subharmonic and superharmonic components in frequency spectrums of $P_{d}$ and $P_{\text {in }}$ can be used to characterize nonlinear features of the cracked blade.

4.3. Bifurcation Diagrams of $P_{d}$ and $P_{\text {in }}$ under Different Breathing Cracks. In order to further explore nonlinear dynamic characteristics of the rotated blade under different sizes of breathing cracks, bifurcation diagrams are calculated by resampling $P_{d}$ and $P_{\text {in }}$. Firstly, the depth $a$ of the breathing crack is considered. Parameters of the breathing crack are chosen as $l_{c}=40 \mathrm{~mm}$ and other parameters are fixed as the above. The results are shown in Figure 7 and we can see that the depth $a$ has obvious effects on nonlinear dynamic responses of the rotated cracked blade. With the increase of the depth $a$, the following bifurcation phenomena can be observed in Figure 7(a). (i) When it changes from $0 \mathrm{~mm}$ to $1.46 \mathrm{~mm}$, the response of $P_{d}$ is a single-period motion. (ii) When it changes from $1.46 \mathrm{~mm}$ to $1.62 \mathrm{~mm}$, the response of 


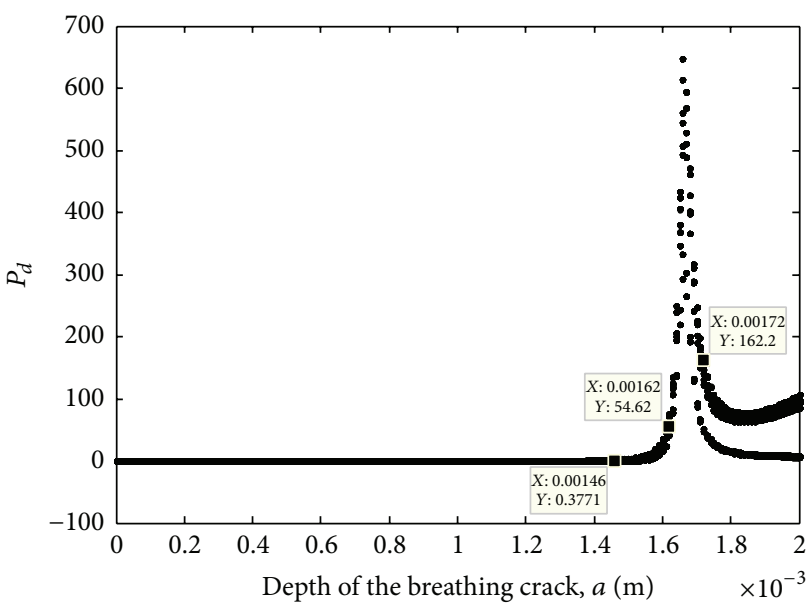

(a) Bifurcation diagram by sampling $P_{d}$

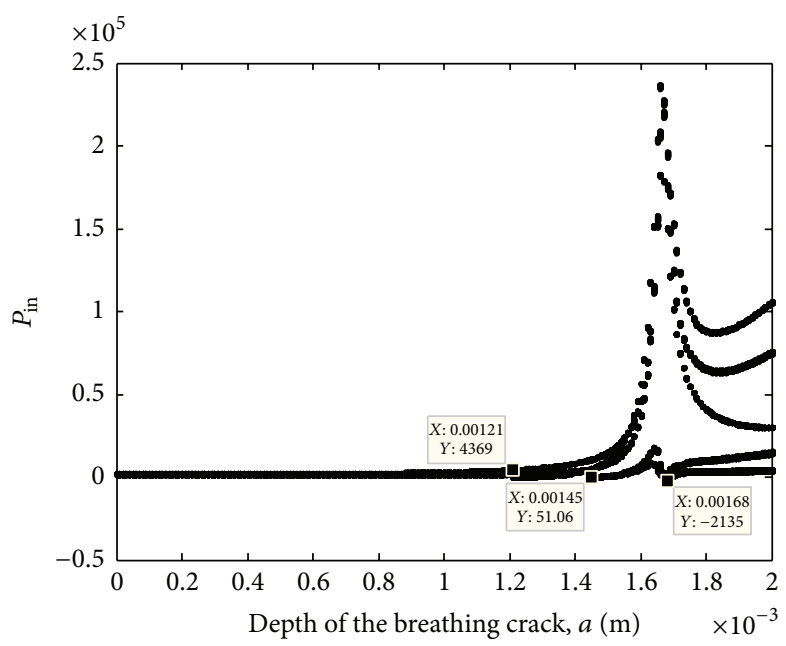

(b) Bifurcation diagram by sampling $P_{\text {in }}$

FIGURE 7: Bifurcation diagrams with the depth of the breathing crack $a$.

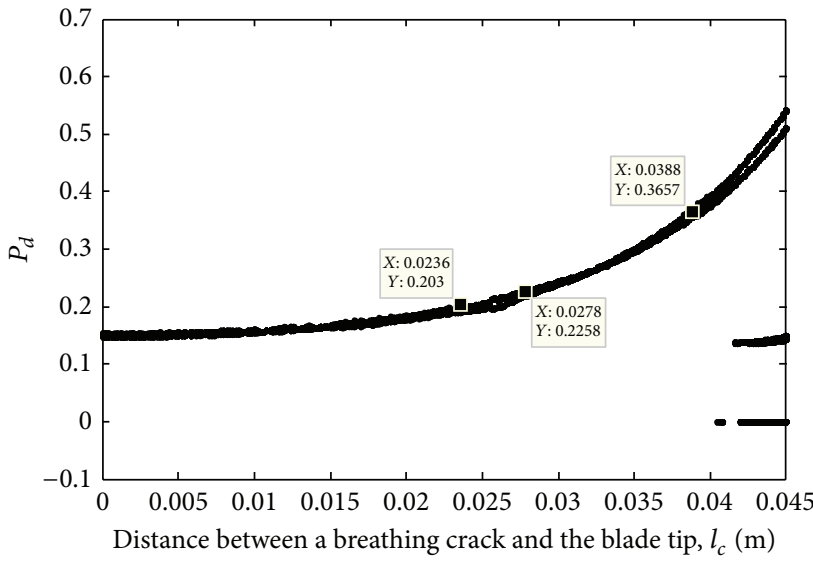

(a) Bifurcation diagram by sampling $P_{d}$

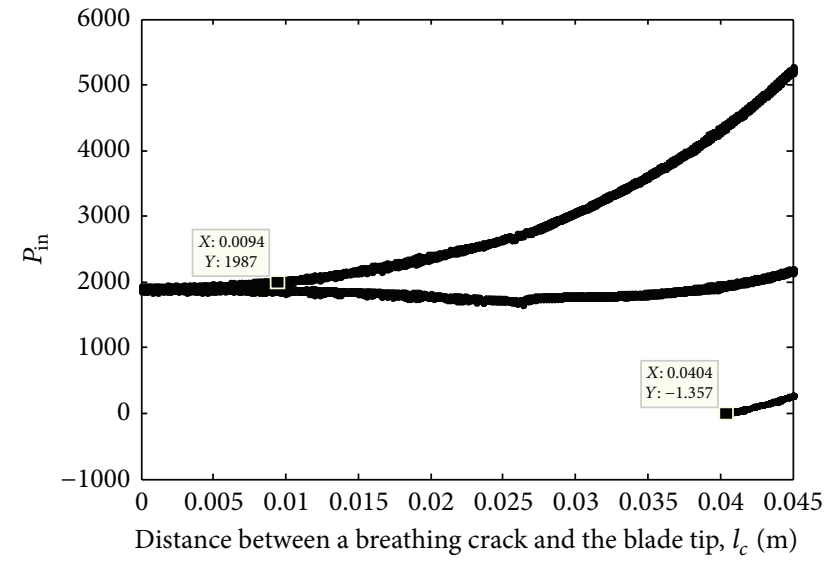

(b) Bifurcation diagram by sampling $P_{\text {in }}$

FIgURE 8: Bifurcation diagrams with the distance $\left(l_{c}\right)$.

$P_{d}$ is a double-period motion. (iii) When it changes from $1.62 \mathrm{~mm}$ to $1.72 \mathrm{~mm}$, the response of $P_{d}$ is a single-period motion. (iv) When it changes from $1.72 \mathrm{~mm}$ to $2 \mathrm{~mm}$, the response of $P_{d}$ is a multiperiod motion. Similar bifurcations phenomena of $P_{\text {in }}$ under different depths of the breathing crack are shown in Figure 7(b), for example, from singleperiod motion, double-period motion, and triple-period motion to multiperiod motion.

Secondly, the distance $l_{c}$ between the breathing crack and the blade tip is considered. Here $a=1.2 \mathrm{~mm}$ and other parameters are fixed as the above. Bifurcation diagrams by resampling $P_{d}$ and $P_{\text {in }}$ are shown in Figure 8 . It can be seen that the distance $l_{c}$ also has obvious effects on nonlinear dynamic responses of the rotated cracked blade. With the increase of the distance $l_{c}$, the following bifurcation phenomena can be observed in Figure 8(a). (i) When $l_{c}$ changes from $0 \mathrm{~mm}$ to $23.6 \mathrm{~mm}$, the response of $P_{d}$ is a single-period motion. (ii) When $l_{c}$ changes from $23.6 \mathrm{~mm}$ to $27.8 \mathrm{~mm}$, the response of $P_{d}$ is a double-period motion. (iii) When $l_{c}$ changes from $27.8 \mathrm{~mm}$ to $38.8 \mathrm{~mm}$, the response of $P_{d}$ is a single-period motion. (iv) When $l_{c}$ changes from $38.8 \mathrm{~mm}$ to $45 \mathrm{~mm}$, the response of $P_{d}$ is a multiperiod motion. Similar bifurcation phenomena of $P_{\text {in }}$ under different distances are shown in Figure 8(b), for example, from singleperiod motion and double-period motion to triple-period motion.

4.4. Superharmonic/Subharmonic Resonance Factors of a Breathing Crack in the Rotated Blade. Based on the above numerical analysis, we can see that both the depth and the position of a breathing crack in the rotated blade will affect nonlinear behaviors of the cracked blade. In particular, superharmonic or/and subharmonic resonances due to the breathing crack will occur in blade displacements, $P_{d}$ and $P_{\text {in }}$. In order to quantify this kind of nonlinear dynamic 


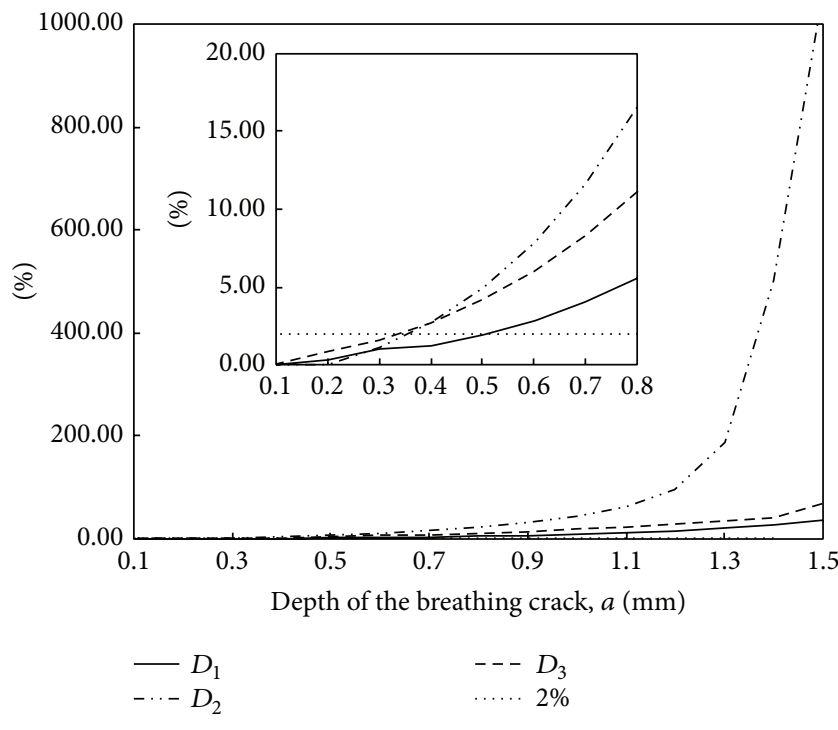

FIgURE 9: The curves of $D_{1}, D_{2}$, and $D_{3}$ with $a$.

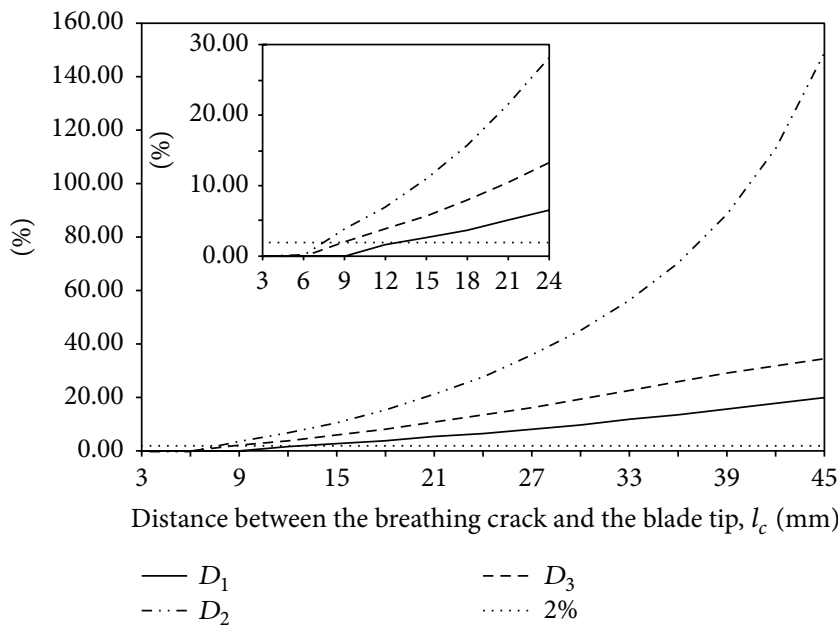

Figure 10: The curves of $D_{1}, D_{2}$, and $D_{3}$ with $l_{c}$.

behaviors, superharmonic/subharmonic resonance factors $\left(D_{1}, D_{2}\right.$, and $\left.D_{3}\right)$ are defined, respectively, as follows:

$$
\begin{aligned}
& D_{1}=\frac{P_{1}}{P_{2}} \times 100 \%, \\
& D_{2}=\frac{P_{3}}{P_{4}} \times 100 \%, \\
& D_{3}=\frac{P_{5}}{P_{6}} \times 100 \%,
\end{aligned}
$$

where $P_{1}$ and $P_{2}$ are the amplitudes at the superharmonic frequency $\left(2 \omega_{0}\right)$ and fundamental frequency $\left(\omega_{0}\right)$ in the frequency spectra of blade displacements, respectively. $P_{3}$ and $P_{4}$ are the amplitudes at the subharmonic frequency $\left(\omega_{1} / 2\right)$ and fundamental frequency $\left(\omega_{1}\right)$ in the frequency spectra of $P_{d}$, respectively. $P_{5}$ and $P_{6}$ are the amplitudes at the subharmonic frequency $\left(\omega_{1} / 2\right)$ and fundamental frequency $\left(\omega_{1}\right)$ in the frequency spectra of $P_{\mathrm{in}}$, respectively.
Firstly, the depth $a$ of the crack is considered. Here $l_{c}=$ $40 \mathrm{~mm}$ and all other parameters are fixed as the above. The relations between $D_{1}, D_{2}$, and $D_{3}$ and $a$ are shown in Figure 9 , respectively. It can be seen that $D_{1}, D_{2}$, and $D_{3}$ increase nonlinearly with $a$. For given $a$ under the condition of $a>$ $0.2 \mathrm{~mm}$, both $D_{2}$ and $D_{3}$ are much more than $D_{1}$. Assuming that the threshold value of detecting a breathing crack is set as $2 \%$, it can be seen that $a$ needs to be larger than $0.51 \mathrm{~mm}$ by using $D_{1}$, while $a$ only needs to be larger than $0.35 \mathrm{~mm}$ by using $D_{2}$ or $D_{3}$. It testifies that $D_{2}$ and $D_{3}$ are more sensitive to the depth of the crack than $D_{1}$. In particular, $D_{2}$ is the most sensitive parameter and increases sharply once $a>1.3 \mathrm{~mm}$.

Secondly, the distance $\left(l_{c}\right)$ between the breathing crack and the blade tip is considered. Here, $a=1.2 \mathrm{~mm}$ and other parameters are fixed as the above. The relations between $D_{1}$, $D_{2}$, and $D_{3}$ and $l_{c}$ are shown in Figure 10. It can be seen that $D_{1}, D_{2}$, and $D_{3}$ also increase with $l_{c}$. For given $l_{c}$ under the condition of $l_{c}>6 \mathrm{~mm}$, both $D_{2}$ and $D_{3}$ are much more than $D_{1}$. It testifies that $D_{2}$ and $D_{3}$ are more sensitive to the distance $\left(l_{c}\right)$ than $D_{1}$. In particular, $D_{2}$ is the most sensitive parameter. In other words, when the breathing crack is close to the tip, it is easier to detect it by using $D_{2}$ or $D_{3}$ than by using $D_{1}$.

\section{Conclusions}

Accurate detection of small cracks in rotated blades is very significant for safety, reliability, and availability. In practice, a breathing crack model is more fit for a small crack in a rotated blade than other models. However, traditional vibration displacements-based methods are less sensitive to nonlinear characteristics due to small breathing cracks. In this paper, vibration power flow analysis (VPFA) is introduced to solve this problem. Firstly, local flexibility due to a crack is derived and then time-varying dynamic model of the rotated blade with a small breathing crack is built. Then, based on it, the corresponding vibration power flow model of the blade with a breathing crack is proposed. Finally, VPFA-based numerical simulations are done to expose nonlinear behaviors of the cracked blade. Main conclusions include the following. (i) Nonlinear behaviors of a crack can be enhanced by power flow analysis, so VPFA is more sensitive to a small breathing crack than displacements-based vibration analysis. (ii) With the changes of the breathing crack, bifurcations will occur in $P_{d}$ and $P_{\text {in }}$, such as from single-period motion and double-period motion to multiperiod motion. (iii) When a small breathing crack occurs in the rotated blade, 1/2-order subharmonic and 3/2-order superharmonic components will appear in frequency spectra of $P_{d}$ and $P_{\text {in }}$. Furthermore, more high-order superharmonic components will appear with the increase of the depth of the breathing crack. (iv) Two subharmonic resonance factors $\left(D_{2}\right.$, and $\left.D_{3}\right)$ are defined based on VPFA. $D_{2}$ is the most sensitive to the location and depth of a crack. All results demonstrate that VPFA is a promising way to detect and predict small breathing cracks in rotated blades.

However, it must be noted that the cracked blades are simplified as rotated cantilever beams in this paper and the 
first-order flexural vibration is only considered. Indeed, many other parameters are not studied in this paper, including damping, rotary inertia, and coupling of flexural and longitudinal vibrations. Also, for practical engineering applications, first one needs to verify the damage model assumption. Therefore, further works should be done to improve dynamic model of rotated blades with breathing cracks.

\section{Competing Interests}

The authors declare that there are no competing interests regarding the publication of this paper.

\section{Acknowledgments}

This work was supported by the National Basic Research Program of China (Grant no. 2015 CB057400).

\section{References}

[1] E. P. Petrov and D. J. Ewins, "Analysis of the worst mistuning patterns in bladed disk assemblies," Journal of Turbomachinery, vol. 125, no. 4, pp. 623-631, 2003.

[2] Y.-J. Chan and D. J. Ewins, "Management of the variability of vibration response levels in mistuned bladed discs using robust design concepts. Part 1: parameter design," Mechanical Systems and Signal Processing, vol. 24, no. 8, pp. 2777-2791, 2010.

[3] M. Witoś, "High sensitive methods for health monitoring of compressor blades and fatigue detection," The Scientific World Journal, vol. 2013, Article ID 218460, 31 pages, 2013.

[4] T. G. Chondros, A. D. Dimarogonas, and J. Yao, "A continuous cracked beam vibration theory," Journal of Sound and Vibration, vol. 215, no. 1, pp. 17-34, 1998.

[5] A. D. Dimarogonas, S. A. Paipetis, and T. G. Chondros, Analytical Methods in Rotor Dynamics, vol. 9, Springer, Dordrecht, The Netherlands, 2nd edition, 2013.

[6] T. G. Chondros and A. D. Dimarogonas, "Identification of cracks in welded joints of complex structures," Journal of Sound and Vibration, vol. 69, no. 4, pp. 531-538, 1980.

[7] A. A. Masoud and S. Al-Said, "A new algorithm for crack localization in a rotating Timoshenko beam," Journal of Vibration and Control, vol. 15, no. 10, pp. 1541-1561, 2009.

[8] J. H. Kuang and B. W. Huang, "The effect of blade crack on mode localization in rotating bladed disks," Journal of Sound and Vibration, vol. 227, no. 1, pp. 85-103, 1999.

[9] A. C. Chasalevris and C. A. Papadopoulos, "Identification of multiple cracks in beams under bending," Mechanical Systems and Signal Processing, vol. 20, no. 7, pp. 1631-1673, 2006.

[10] D. G. Smith and C. W. Smith, "A photoelastic evaluation of the influence of closure and other effects upon the local bending stresses in cracked plates," International Journal of Fracture Mechanics, vol. 6, no. 3, pp. 305-318, 1970.

[11] S. Christides and A. D. S. Barr, "Torsional vibration of cracked beams of non-circular cross-section," International Journal of Mechanical Sciences, vol. 28, no. 7, pp. 473-490, 1986.

[12] Z. S. Chen, Y. M. Yang, Y. Xie, B. Guo, and Z. Hu, "Noncontact crack detection of high-speed blades based on principal component analysis and Euclidian angles using optical-fiber sensors," Sensors and Actuators A: Physical, vol. 201, no. 10, pp. 66-72, 2013.
[13] S. Masoud, M. A. Jarrah, and M. Al-Maamory, "Effect of crack depth on the natural frequency of a prestressed fixed-fixed beam," Journal of Sound and Vibration, vol. 214, no. 2, pp. 201212, 1998.

[14] A. Said, S. Masoud, M. Naji, A. Adnan, and A. Shukry, "Flexural vibration of rotated cracked timoshenko beam," Journal of Vibration and Control, vol. 12, no. 11, pp. 1271-1287, 2006.

[15] J. A. Loya, L. Rubio, and J. Fernández-Sáez, "Natural frequencies for bending vibrations of Timoshenko cracked beams," Journal of Sound and Vibration, vol. 290, no. 3-5, pp. 640-653, 2006.

[16] G. Yan, A. De Stefano, E. Matta, and R. Feng, "A novel approach to detecting breathing-fatigue cracks based on dynamic characteristics," Journal of Sound and Vibration, vol. 332, no. 2, pp. 407-422, 2013.

[17] D. Broda, V. Hiwarkar, V. V. Silberschmidt, and W. J. Staszewski, "Effect of crack induced nonlinearity on dynamics of structures: application to structural health monitoring," Journal of Physics: Conference Series, vol. 451, no. 1, article 012015, 2013.

[18] A. Chatterjee, "Nonlinear dynamics and damage assessment of a cantilever beam with breathing edge crack," Journal of Vibration and Acoustics, vol. 133, no. 5, Article ID 051004, 2011.

[19] U. Andreaus and P. Baragatti, "Cracked beam identification by numerically analysing the nonlinear behaviour of the harmonically forced response," Journal of Sound and Vibration, vol. 330, no. 4, pp. 721-742, 2011.

[20] M. Meier, O. V. Shiryayev, and J. C. Slater, "Investigation of candidate features for crack detection in fan and turbine blades and disks," in Proceedings of the 50th AIAA/ASME/ASCE/AHS/ASC Structures, Structural Dynamics and Materials Conference, May 2009.

[21] S. M. Cheng, A. S. J. Swamidas, X. J. Wu, and W. Wallace, "Vibrational response of a beam with a breathing crack," Journal of Sound and Vibration, vol. 225, no. 1, pp. 201-208, 1999.

[22] E. Douka and L. J. Hadjileontiadis, "Time-frequency analysis of the free vibration response of a beam with a breathing crack," NDT and E International, vol. 38, no. 1, pp. 3-10, 2005.

[23] M. Rezaee and R. Hassannejad, "Free vibration analysis of simply supported beam with breathing crack using perturbation method," Acta Mechanica Solida Sinica, vol. 23, no. 5, pp. 459470, 2010.

[24] M. Rezaee and R. Hassannejad, "A new approach to free vibration analysis of a beam with a breathing crack based on mechanical energy balance method," Acta Mechanica Solida Sinica, vol. 24, no. 2, pp. 185-194, 2011.

[25] U. Andreaus, P. Casini, and F. Vestroni, "Non-linear dynamics of a cracked cantilever beam under harmonic excitation," International Journal of Non-Linear Mechanics, vol. 42, no. 3, pp. 566-575, 2007.

[26] M. Kulyk, O. Kucher, V. Kharyton, J.-P. Laine, and F. Thouverez, "Dynamic non-linear analysis of a cracked blade," Aviation, vol. 12, no. 3, pp. 66-79, 2008.

[27] C. Liu and D. Jiang, "Crack modeling of rotating blades with cracked hexahedral finite element method," Mechanical Systems and Signal Processing, vol. 46, no. 2, pp. 406-423, 2014.

[28] H. G. D. Goyder and R. G. White, "Vibrational power flow from machines into built-up structures, part I: introduction and approximate analyses of beam and plate-like foundations," Journal of Sound and Vibration, vol. 68, no. 1, pp. 59-75, 1980.

[29] G. Zhang, M. Castanier, C. Pierre, and Z. Mourelatos, "Vibration and power flow analysis of a vehicle structure using characteristic constraint modes," SAE Technical Paper 2003-011602, 2003. 
[30] X. Zhu, T. Y. Li, Y. Zhao, and J. X. Liu, "Structural power flow analysis of Timoshenko beam with an open crack," Journal of Sound and Vibration, vol. 297, no. 1-2, pp. 215-226, 2006.

[31] J. Yang, Y. P. Xiong, and J. T. Xing, "Power flow behaviour and dynamic performance of a nonlinear vibration absorber coupled to a nonlinear oscillator," Nonlinear Dynamics, vol. 80, no. 3, pp. 1063-1079, 2015.

[32] T. G. Chondros, A. D. Dimarogonas, and J. Yao, "Vibration of a beam with a breathing crack," Journal of Sound and Vibration, vol. 239, no. 1, pp. 57-67, 2001.

[33] A. D. Dimarogonas, Vibration for Engineers, Prentice-Hall, 2nd edition, 1996.

[34] G. Genta, Dynamics of Rotated Systems, Springer Press, Berlin, Germany, 2005.

[35] H. Diken and K. Alnefaie, "Effect of unbalanced rotor whirl on blade vibrations," Journal of Sound and Vibration, vol. 330, no. 14, pp. 3498-3506, 2011.

[36] X. Yong, Non-contact on-line detection and diagnosis of abnormal vibrations of high-speed rotated blades [M.S. thesis], National University of Defense Technology, Changsha, China, 2012. 


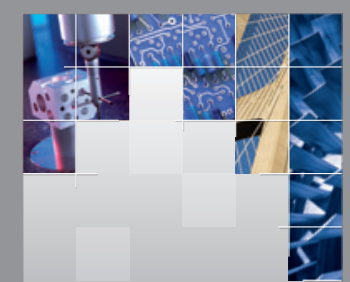

\section{Enfincering}
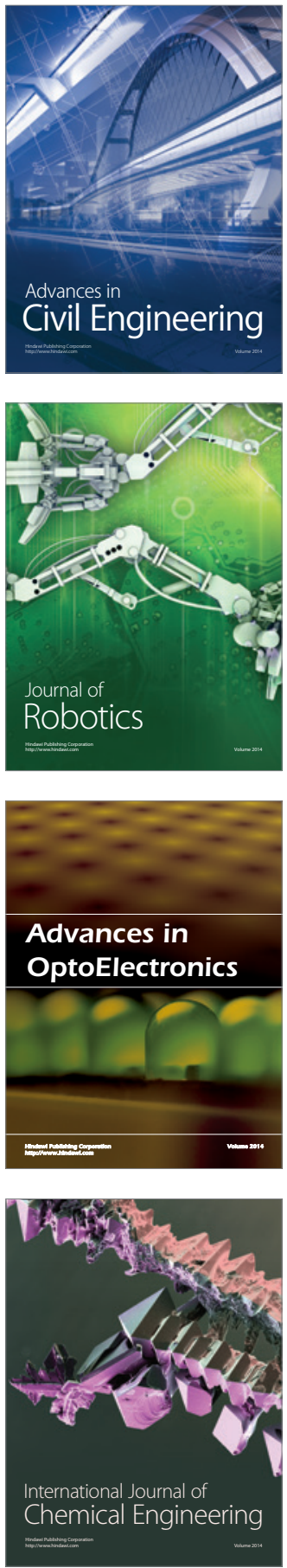

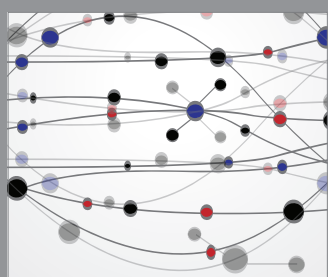

The Scientific World Journal

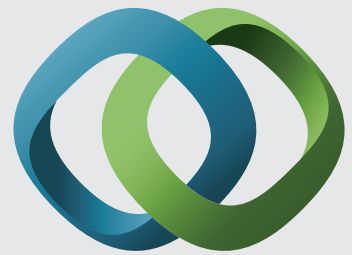

\section{Hindawi}

Submit your manuscripts at

http://www.hindawi.com
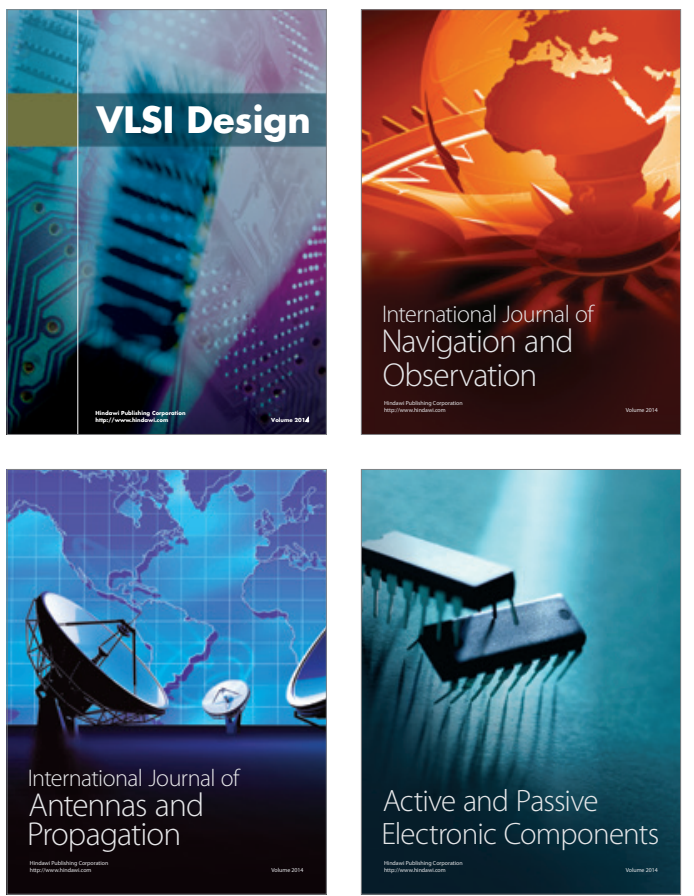
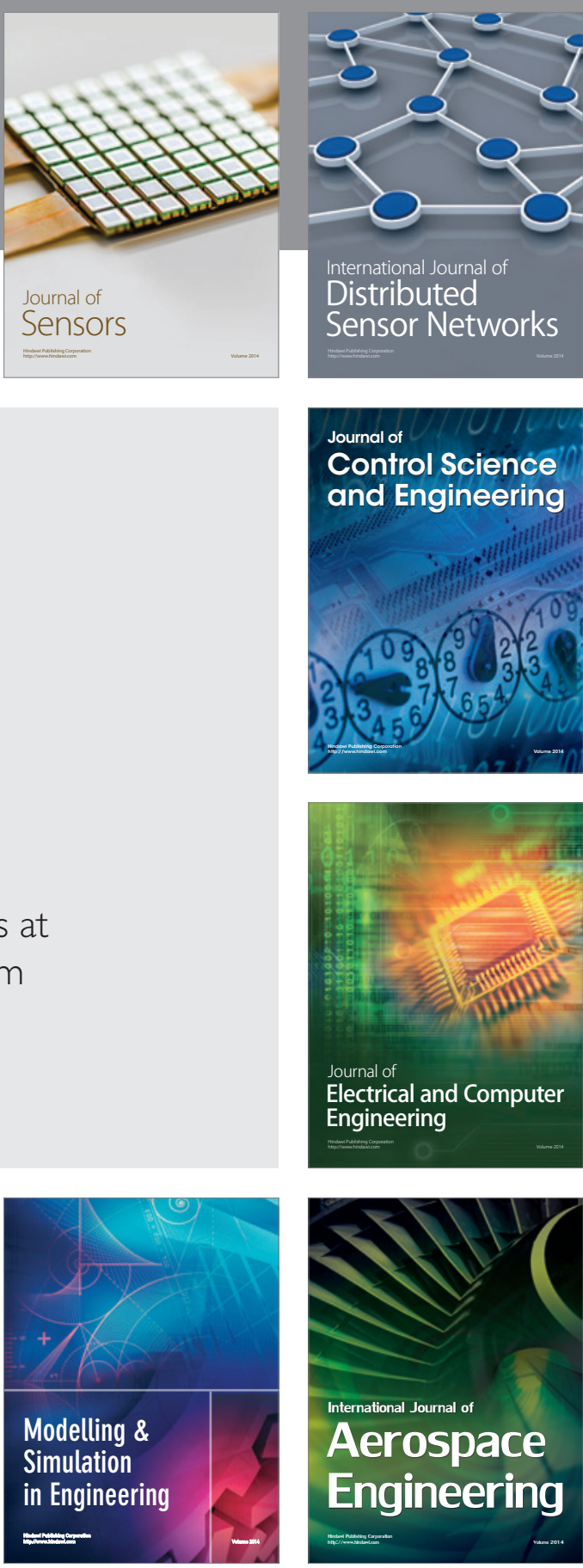

International Journal of

Distributed

Sensor Networks

Journal of

Control Science

and Engineering
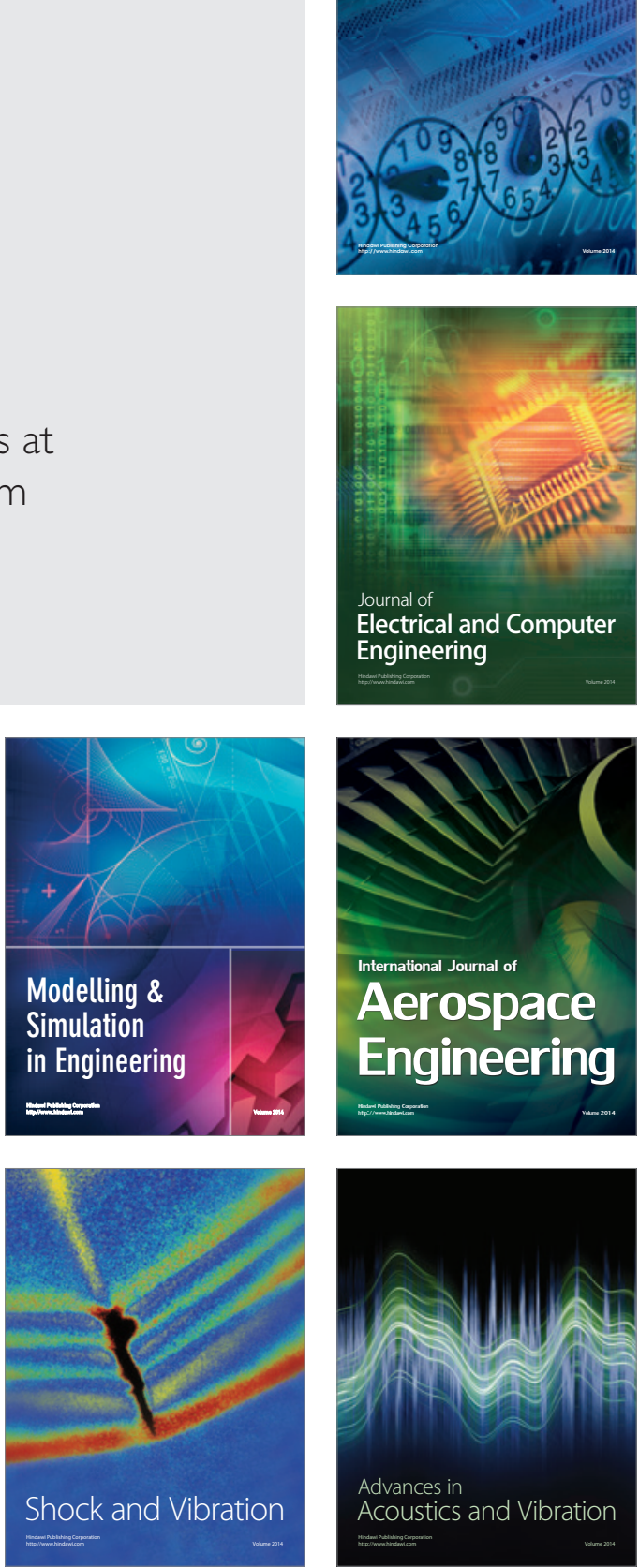